\title{
Influence of annealing parameters on the mechanical properties of heterogeneous lamella structured 5083 aluminum alloy
}

\author{
X. T. Fang ${ }^{\dagger, 1}$, G. Z. He ${ }^{1,2}$, M. Ruiz' ${ }^{1}$ C. Zheng ${ }^{3}$, Y. F. Wang ${ }^{1,4}$, Z. K. Li ${ }^{1,5}$, Y. T. Zhu ${ }^{1,6}$ \\ †xfang4@ncsu.edu \\ ${ }^{1}$ Department of Materials Science and Engineering, North Carolina State University, Raleigh, NC 27695, USA \\ ${ }^{2}$ Department of Microsystems - IMS, Faculty of Technology, Natural Sciences and Maritime Sciences, \\ University of South-Eastern Norway, Postboks 235, 3603, Kongsberg, Norway \\ ${ }^{3}$ Department of Nuclear Engineering, North Carolina State University, Raleigh, NC 27695, USA \\ ${ }^{4}$ School of Aeronautics and Astronautics, Sichuan University, Chengdu, 610065, China \\ ${ }^{5}$ Key Laboratory for Anisotropy and Texture of Materials (Ministry of Education), Northeastern University, \\ Shenyang, 110819, China \\ ${ }^{6}$ Nano and Heterogeneous Structural Materials Center, Nanjing University of Science and Technology, \\ Nanjing, 210094, China
}

It has long been a research goal to obtain both high strength and ductility in structural materials. As the most important structural materials, metals and alloys are either strong or ductile, but seldom maintain both characteristics at the same time. After decades of attempts, extraordinary high strength has been achieved by involving nano- or ultrafine-grained structure. However, the ductility of these materials is relatively low. In the recent years, heterostructured materials have been demonstrated to possess superior combinations of strength and ductility, which are attributed to the hetero-deformation induced (HDI) strengthening and work hardening. The HDI hardening in previous studies is mainly caused by soft/hard domain boundaries. Here we report a heterogeneous lamella structure (HLS) in 5083 aluminum alloy fabricated by rolling and partial annealing. Superior combinations of strength and ductility have been achieved in the HLS Al-5083 through various annealing times and temperatures in this paper. Based on EBSD and TEM analysis, HDI hardening is an important reason for the excellent combination of strength and ductility. And soft/domain boundary hardening, and precipitation hardening are revealed as two important components of HDI hardening in Al-5083. These findings elucidate the HDI hardening mechanism in Al-5083 alloy, which will help us design the heterostructure of Al-5083 for engineering applications.

Keywords: heterostrctured, hetero-deformation, geometrically necessary dislocation.

\section{Introduction}

Heterostructured materials, defined as materials containing domains with dramatically different flow stresses [1], recently became a hot research topic. Heterostructured materials have been reported to have a good solution of strength and ductility $[1,2]$, which is attributed to their ability to produce hetero-deformation induced (HDI) strengthening to enhance strength and HDI hardening to retain ductility [3]. Several diverse types of heterostructured materials have been reported, including bimodal materials [4-6], gradient materials [7-10], heterogeneous lamella materials [2,11], harmonic structure [12-14], dual-phase steel [15-17], laminate structure $[3,18,19]$, etc, among which heterogeneous lamella structured (HLS) materials are conducive to engineering applications, since they can be produced using industrial facilities at large scale and low cost.

$\mathrm{Wu}$ et al. [2] fabricated HLS Ti with high strength of nanostructured Ti while maintaining the ductility of coarsegrain Ti by rolling and partial annealing. Following a similar procedure, Li et al. [11] produced HLS 316L stainless steel with an excellent combination of strength and ductility.
However, researchers in the material science community still doubt whether the principle of HDI strengthening can be extended to all commercial alloys, since rolling and partial annealing behaviors are highly sensitive to the annealing parameters. Moreover, there are limited studies on the effect of annealing conditions on HDI hardening. To verify that rolling and partial annealing is promising for engineering applications, we need to study the sensitivity of the mechanical properties of HLS materials to annealing parameters, i.e. annealing time and temperature, because of the narrow processing parameter window.

Aluminum 5083 alloy was selected in this study, since it is a widely used commercial alloy for ships, bridges, cars, and even missiles components. As a popular commercial alloy, Al-5083 has been well studied by the material community. However, there are few reports on processing heterostructures in Al-5083. In this study, HLS Al-5083 was fabricated by rolling and partial annealing. The annealing temperatures ranged from $175^{\circ}$ to $300^{\circ}$, and annealing times ranged from 5 to 40 minutes. The evolution of mechanical properties under different annealing temperature was studied by uniaxial tensile tests. 


\section{Experiments}

A commercial 5083 Aluminum alloy plate was annealed at $500^{\circ}$ for 2 hours to obtain a uniform coarse-grained (CG) structure. CG plates were rolled (represented by "R") from $10 \mathrm{~mm}$ to $2 \mathrm{~mm}$ (80\% thickness reduction), and each pass produced $\sim 5 \%$ thickness reduction. Subsequently, the rolled Al-5083 alloys were annealed ("A").

Samples for EBSD observation were first cut from the rolled and annealed samples and then mechanically polished to achieve a mirror-like surface. Electrochemical polishing was performed for under 30 seconds to remove the strained top-surface layer. The electrolyte consisted of nitric acid (concentration of $85 \%$ ), ethanol, and deionized water with a volume ratio of 1:1:3. EBSD was conducted in an FEI Quanta 3D FEG dual-beam instrument and each EBSD scan was performed under $20 \mathrm{kV}$ and $16 \mathrm{nA}$ electron beam and with a bin size of $2 \times 2$ to achieve a decent angular resolution $[31,32]$.

TEM foil samples were prepared by mechanically polishing the specimen to $100 \mu \mathrm{m}$, followed by twin-jet polishing at $-30^{\circ}$. The electrolyte was the same as for the electrochemical polishing step. TEM observation was performed in a JOEL2000 microscope operating at $200 \mathrm{kV}$.

Dog-bone shaped tensile samples with gauge dimensions of $10 \times 2 \times 2 \mathrm{~mm}^{3}$ were tested under uniaxial tension on a Shimadzu AGS machine. Both normal and unloadingreloading tension tests were carried out at room temperature at a strain rate of $5 \times 10^{-4} \mathrm{~s}^{-1}$, and each test was repeated for at least 3 samples to ensure data reproducibility.

\section{Results}

Fig. 1 shows the microstructure of a rolled sample (R80) before (Fig. 1a) and after (Fig. 1a) partial annealing (A) at $230^{\circ}$ for 10 mins. Fig. 1a shows that a high density of dislocation entanglements and dislocation walls were formed inside Al-5083 after rolling. Since Al-5083 has high stacking fault energy $\left(>50 \mathrm{~mJ} / \mathrm{m}^{2}\right)$ [20], the refinement of grains was produced by dislocation accumulation and interactions [21]. A high density of dislocations is generated during plastic deformation, which will subsequently form dislocation walls and entanglements. Upon further straining, these dislocation walls become subgrains. The subgrains, as well as remained dislocation cells, provides nucleation sites for recrystallization and form new ultrafine grains after partial recrystallization, which produced some equiaxed grains (Fig. 1b).

EBSD data (Fig. 2) also shows that a heterostructure has been formed after partial recrystallization. Two types of domains are clearly shown in Fig. 2. The first is large domains consisting of coarse grains, separated by domains of

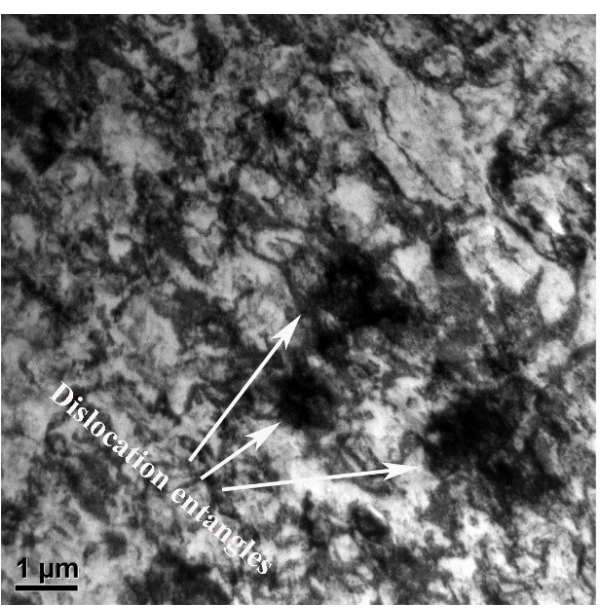

a

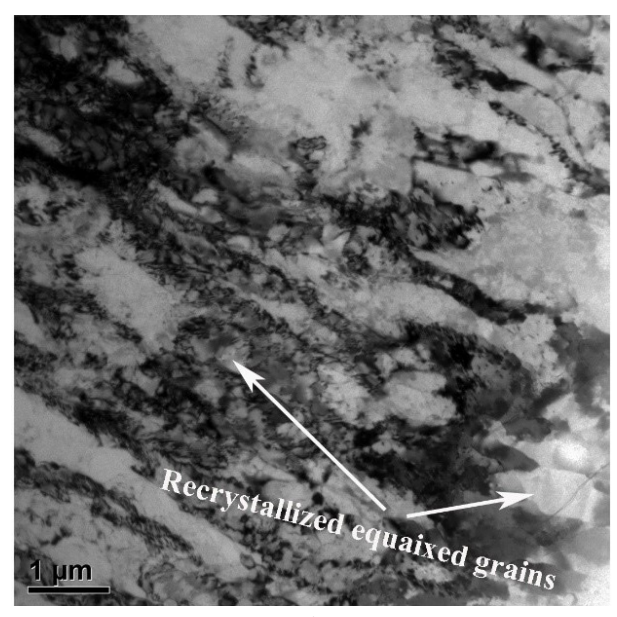

b

Fig. 1. TEM image of rolling $80 \%$ thickness reduction (a); rolling $80 \%$ thickness reduction and partially recrystallized at $230^{\circ} \mathrm{C}$ for $10 \mathrm{mins}(\mathrm{b})$.

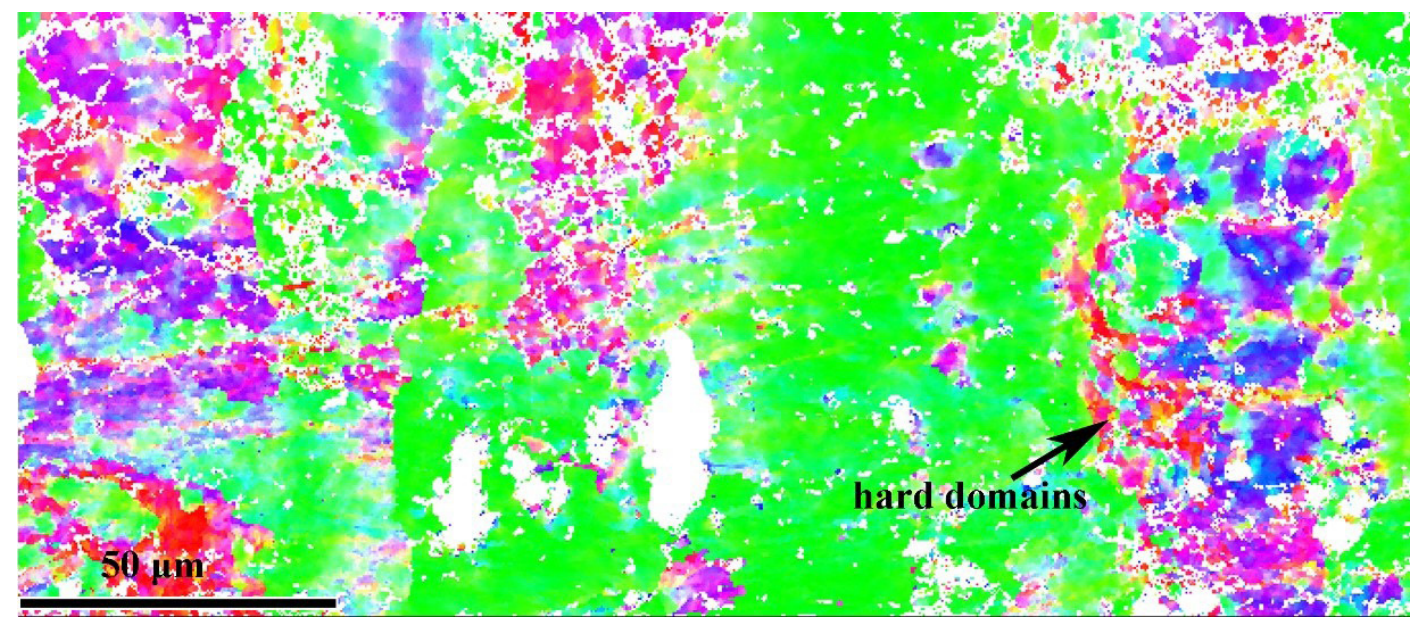

Fig. 2. (Color online) EBSD mapping of an R80+230C_10 mins sample. 
fine grains. These large domains in the same orientation are considered as soft domains. Second, hard domains consisting of small grains, which are likely formed by recrystallization. The volume fraction of these hard domains is $50 \%$, and the distance between two hard domains is $25-40 \mu \mathrm{m}$. Though the distribution of hard domains and soft domains is slightly different from the optimal value $[2,3,18]$, the different flow stress in the hard domains and soft domains will still cause a strain gradient at the interface, which results in HDI stress hardening in HLS Al-5083 [1].

Fig. 3 shows the results of the uniaxial tensile test for different samples. Each condition was tested four times for reproducibility. To investigate the effects of partial annealing temperature on mechanical properties, as-rolled 5083 samples were annealed under different temperature for 5 mins, as shown in Fig. 3 a. From $200^{\circ} \mathrm{C}$ to $230^{\circ} \mathrm{C}$, both yield strength and ultimate strength dropped by $\sim 20 \%$. However, uniform elongation increased by $76 \%$. With increasing annealing temperatures below $300^{\circ} \mathrm{C}$, yield strength slightly dropped, but ductility increased. Above $300^{\circ} \mathrm{C}$, yield strength significantly decreased.

The yield strength and uniform elongation of samples annealed at $300^{\circ} \mathrm{C}$ for 5 mins are similar to coarse grained $\mathrm{Al}-5083$ (annealed at $500^{\circ} \mathrm{C}$ for $2 \mathrm{~h}$ ), which indicates grain growth rate is high over $300^{\circ} \mathrm{C}$. The ultimate stress reached a plateau between $230^{\circ} \mathrm{C}$ and $270^{\circ} \mathrm{C}$. Based on the combinations of yield strength and uniform elongation, $230^{\circ} \mathrm{C}$ was selected for further investigation on partial recrystallization time influence. As shown in Fig. 3 b, the yield strength dropped by $80 \mathrm{MPa}$ after $5 \mathrm{mins}$ annealing, then dropped slowly with increasing time, accompanied by a significant increase in uniform elongation. With increasing annealing time, the combination of strength and uniform elongation remains. Combination of yield strength and uniform elongation is plotted in Fig. 4, which indicates that our HLS Al-5083 has a superior combination of strength and ductility, as compared with other structures. Moreover, in a wide range of annealing temperature and annealing time, the mechanical property is stable. Therefore, rolling and partial annealing is an effective method in fabricating HLS Al-5083 with good combination of strength and ductility.

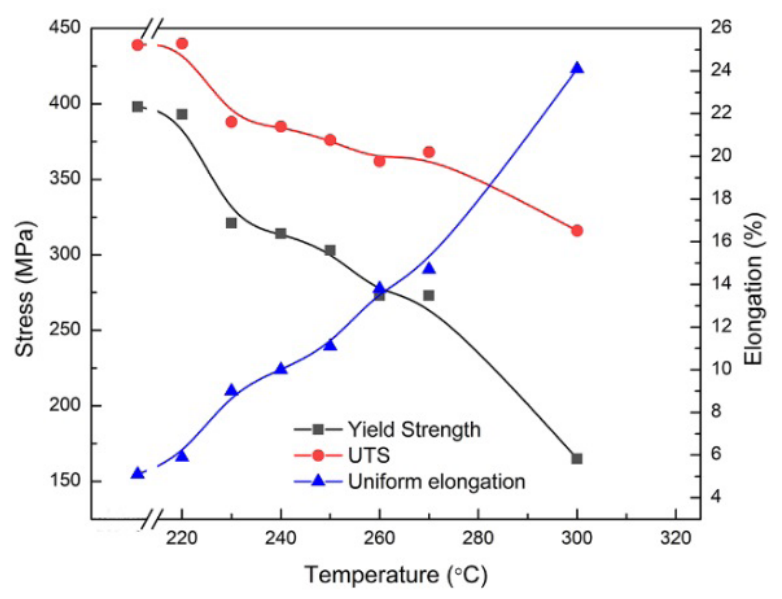

a

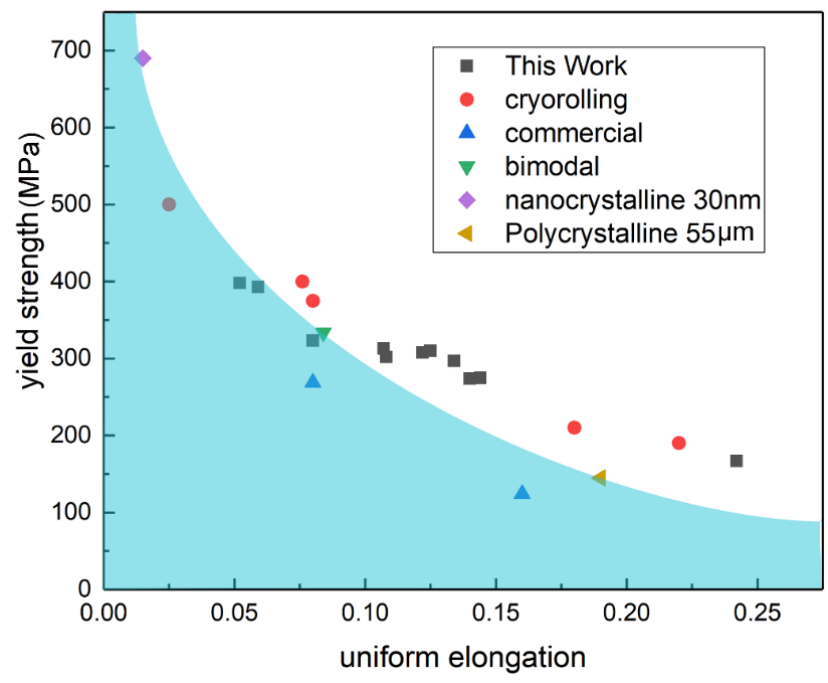

Fig. 4. (Color online) A comparison of yield strength and uniform elongation of Al-5083 between this work and other data [22-24].

\section{Discussion}

\subsection{Microstructural Evolution}

Detailed microstructural features are investigated using TEM and EBSD. Fig. 1 shows a high density of dislocation entanglements, which were formed during rolling. Due to the high stacking fault energy of aluminum alloys [20,25], dislocation slip occurred at the early plastic deformation stage. Slip systems were activated in coarse grains to accommodate the imposed plastic strain. Dislocation walls and dislocation entangled zones then started to form, which divided grains into volume elements called cell blocks. With increasing strain, the misorientation angles between different cell blocks increased. Eventually, new grains formed at the place of cell blocks [21]. Meanwhile, Al-5083 plates were not deformed homogeneously by cold rolling at ambient temperature [26] which could induce heterogeneity of nucleation and grain growth during partial annealing.

After partial recrystallization, two types of domains are shown in EBSD images: soft domains and hard domains.

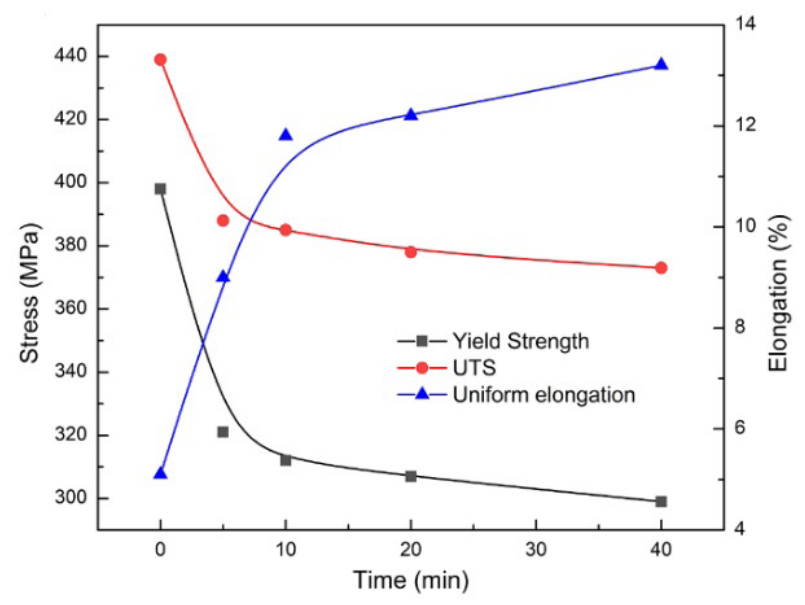

b

Fig. 3. (Color online) Stress and uniform elongation of different conditions: different annealing temperatures for 5 min annealing (a), different annealing times for annealing at $230^{\circ} \mathrm{C}(\mathrm{b})$. 
A soft domain is the aggregation of coarse grains $(>1 \mu \mathrm{m})$ and hard domains consisted of ultrafine grains. In our partially recrystallized Al-5083, soft domains consisted of grains with mainly [101] orientation and small deviations, whose volume fraction was over $70 \%$. The large, soft domains were recovered from one original grain with subgrain structures. The reason for this is that the high stacking fault energy makes it difficult for grain to be refined in $\mathrm{Al}$ alloys because fewer dislocations are available to create high-angle grain boundaries and also the limited stored energy give rise to easy grain growth [27]. Rolling to $80 \%$ is insufficient for cell blocks and subgrains to transform into new grains inside the original coarse grains, thus, recovery dominated in these coarse grains during annealing and soft domains with only one orientation was formed. However, Al-5083 was not uniformly deformed during rolling. Some local areas with extensive strain would become sources for heterogeneous nucleation. Subsequently, the newly nucleated grains grow slowly during the partial annealing, because of the relatively low annealing temperature [28]. Therefore, the hard domains with ultrafine grains developed in these areas.

\subsection{HDI Strengthening Mechanism}

Hetero-deformation induced hardening (HDI) is one of the most effective strengthening mechanisms in various heterostructured materials $[2,11,18]$. The HDI stress of HLS Al-5083 is shown in Fig. 5 a, and the results were calculated from loading-unloading-reloading (LUR) experiment. The details of the calculation can be found in $[29,30]$. The R80 + A230C_10 mins sample has the highest HDI stress, compared with the coarse-grained and R80 + A230C_40 mins samples. The high HDI stress is attributed to the high yield stress of the HLS Al-5083. Moreover, the HDI hardening rate of R80 + A230C_10 mins, which is the slope of the HDI stress, is even slightly higher than that of R80 + A230C_40 mins. The high HDI hardening rate maintains the total strain hardening rate, causing the high ductility of $\mathrm{R} 80+\mathrm{A} 230 \mathrm{C} \_10 \mathrm{mins}$. Therefore, HDI hardening plays an important role in the work hardening behavior of HLS Al-5083. Different from single-phase materials, the HDI hardening in Al-5083 is not only caused by domain boundaries, but also from the precipitates [31]. These precipitates are marked by arrows in Fig. 5 b in the R80 + A230C_10 mins sample. The sizes of the precipitates vary from $200 \mathrm{~nm}$ to $2 \mu \mathrm{m}$. All precipitates can act as the hard particles in Al-5083, effectively increasing the HDI hardening [31]. Based on Orowan bypass mechanism [32], the HDI stress caused by precipitation is $80-100 \mathrm{MPa}[33,34]$, which is an important constituent of the HDI stress. Therefore, the HDI hardening of HLS Al-5083 consists of two parts, soft/hard domain hardening and precipitation hardening.

\section{Conclusion}

In this work, a heterogeneous lamella structured (HLS) Al-5083 was found to exhibit a superior combination of strength and ductility. The influence of annealing temperature and time was studied, and good combinations of strength and ductility can be achieved for various annealing time and temperature, making the HLS Al-5083 attractive for engineering applications. Hetero-deformation induced (HDI) hardening is demonstrated to be effective in HLS Al-5083. Two parts of HDI hardening, soft/hard domain hardening and precipitation hardening, were found in the HLS Al-5083 sample.

Acknowledgements. This project was supported by the US Army Research Office [W911 NF-12-1-0009]. TEM characterization were performed in part at the AIF facility which is supported by the State of North Carolina and the National Science Foundation [ECCS-1542015]. The AIF is a member of the North Carolina Research Triangle Nanotechnology Network (RTNN), a site in the National Nanotechnology Coordinated Infrastructure (NNCI).

\section{Reference}

1. X. Wu, Y.Zhu. Mater. Res. Lett. 5, 527 (2017). Crossref

2. X. Wu, M. Yang, F. Yuan, G. Wu, Y. Wei, X. Huang, Y.Zhu. Proc. Natl. Acad. Sci. 112, 14501 (2015). Crossref

3. C.X. Huang, Y.F. Wang, X. L. Ma, S. Yin, H. W. Höppel, M. Göken, X. L. Wu, H. J. Gao, Y. T. Zhu. Mater. Today. 21 (7), 713 (2018). $\underline{\text { Crossref }}$

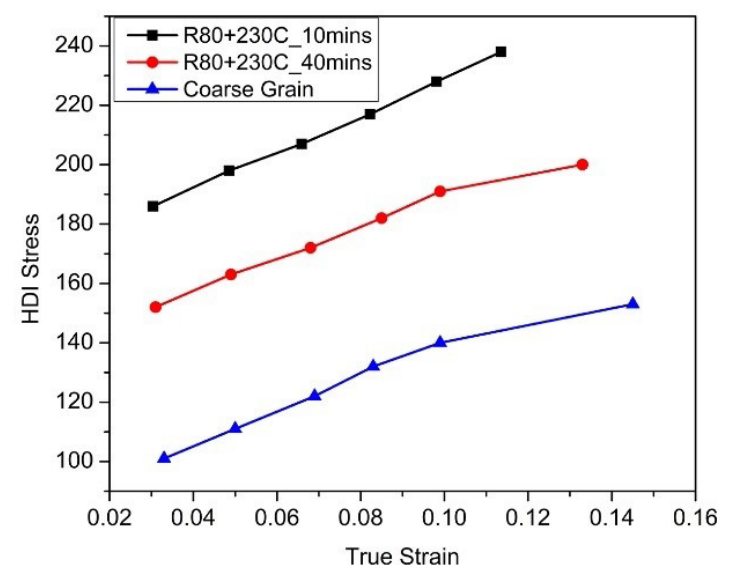

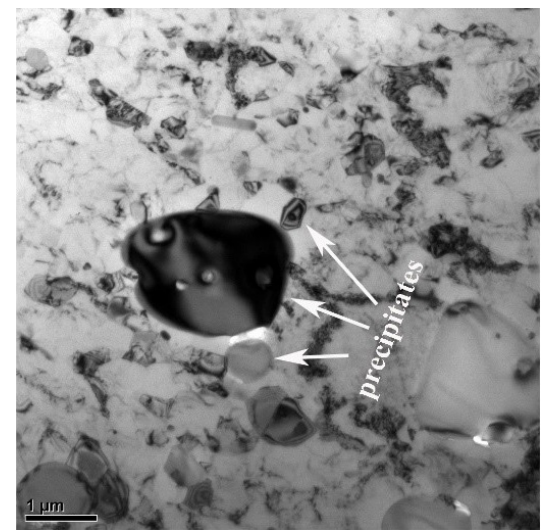

b

Fig. 5. (Color online) HDI stress for three different samples (a); TEM image of precipitates in R80 + A230C_10 mins sample (b). 
4. Y. Wang, M. Chen, F. Zhou, E. Ma. Nature. 419, 912 (2002). Crossref

5. B. O. Han, E. J. Lavernia, Z. Lee, S. Nutt, D. Witkin. Metall. Mater. Trans. A. 36, 957 (2005). Crossref

6. R. Q. Ye, B. Q. Han, E. J. Lavernia. Metall. Mater. Trans. A. 36, 1833 (2005). Crossref

7. T.H. Fang, W.L. Li, N.R. Tao, K.Lu. Science. 331, 1587 (2011). Crossref

8. H. W. Huang, Z. B. Wang, J. Lu, K. Lu. Acta Mater. 87, 150 (2015). Crossref

9. X. Wu, P. Jiang, L. Chen, F. Yuan, Y.T. Zhu. Proc. Natl. Acad. Sci. 111, 7197 (2014). Crossref

10. Z. Cheng, H. Zhou, Q. Lu, H. Gao, L.Lu. Science. 362, eaau1925 (2018). Crossref

11. J. Li, Y. Cao, B. Gao, Y. Li, Y. Zhu. J. Mater. Sci. 53, 10442 (2018). Crossref

12. Z. Zhang, S.K. Vajpai, D. Orlov, K. Ameyama. Mater. Sci. Eng. A. 598, 106 (2014). Crossref

13. S. K. Vajpai, M. Ota, T. Watanabe, R. Maeda, T. Sekiguchi, T. Kusaka, K. Ameyama. Metall. Mater. Trans. A. 46, 903 (2015). rossref

14. C. Sawangrat, S. Kato, D. Orlov, K. Ameyama. J. Mater. Sci. 49, 6579 (2014). Crossref

15. K. Park, M. Nishiyama, N. Nakada, T. Tsuchiyama, S. Takaki. Mater. Sci. Eng. A. 604, 135 (2014). Crossref

16. M. Calcagnotto, Y. Adachi, D. Ponge, D. Raabe. Acta Mater. 59, 658 (2011). Crossref

17. Z. Li, K. G. Pradeep, Y. Deng, D. Raabe, C.C. Tasan. Nature. 534, 227 (2016). Crossref

18. X. Ma, C. Huang, J. Moering, M. Ruppert, H. W. Höppel, M. Göken, J. Narayan, Y.Zhu. Acta Mater. 116, 43 (2016). Crossref

19. I. J. Beyerlein, J. R. Mayeur, S. Zheng, N.A. Mara, J. Wang,
A. Misra. Proc. Natl. Acad. Sci. 111, 4386 (2014). Crossref 20. T.C. Schulthess, P.E. A. Turchi, A. Gonis, T.-G. Nieh. Acta Mater. 46, 2215 (1998). Crossref

21. Y. Cao, S. Ni, X. Liao, M. Song, Y.Zhu. Mater. Sci. Eng. R Rep. 133, 1 (2018). Crossref

22. Y. B. Lee, D. H. Shin, K.-T. Park, W. J. Nam. Scr. Mater. 51, 355 (2004). Crossref

23. V.L. Tellkamp, E. J. Lavernia. Nanostructured Mater. 12, 249 (1999). Crossref

24. K. M. Youssef, R. O. Scattergood, K. L. Murty, C. C. Koch. Scr. Mater. 54, 251 (2006). Crossref

25. Z. Horita, T. Fujinami, M. Nemoto, T.G. Langdon. J. Mater. Process. Technol. 117, 288 (2001). Crossref

26. Q. Xing, X. Huang, N. Hansen. Metall. Mater. Trans. A. 37, 1311 (2006). Crossref

27. K. Neishi, Z. Horita, T. G. Langdon. Mater. Sci. Eng. A. 325, 54 (2002). Crossref

28. H. Miura, T. Sakai, S. Maruoka, J. J. Jonas. Philos. Mag. Lett. 90, 93 (2010). Crossref

29. M. Yang, Y. Pan, F. Yuan, Y. Zhu, X. Wu. Mater. Res. Lett. 4, 145 (2016). $\underline{\text { Crossref }}$

30. R. Xu, G. Fan, Z. Tan, G. Ji, C. Chen, B. Beausir, D.-B. Xiong, Q. Guo, C. Guo, Z. Li, D. Zhang. Mater. Res. Lett. 6, 113 (2018). Crossref

31. K. Tanaka, T. Mori. Acta Metall. 18, 931 (1970). Crossref

32. D. Hull, D. J. Bacon. Introduction to dislocations, 5th ed. Amsterdam, Elsevier, Butterworth-Heinemann (2011) 272 p. $\underline{\text { Crossref }}$

33. H. Zhou, C. Huang, X. Sha, L. Xiao, X. Ma, H. W. Höppel, M. Göken, X. Wu, K. Ameyama, X. Han, Y.Zhu. Mater. Res. Lett. 7, 376 (2019). Crossref

34. Y. Nakayama, T. Takaai, D. Jin. Mater. Sci. Forum. $217-222,1269$ (1996). $\underline{\text { Crossref }}$ 